\title{
Notes on Institutional Exhibits
}

Part III of this book includes more than 1,900 individual entries on degree-granting baccalaureate-or-above institutions and units thereof that are accredited or recognized candidates for accreditation by one of the nine regional agencies (described in Part I). Each institution's description also includes its regional, professional, and institutional accreditation. Those fields in which programs offering specific areas of the profession for accreditation are also indicated. For information on specialized professional accrediting agencies, see Part II of this book. For abbreviations under which the associations are listed, see p. xvii.

The information in Part III was prepared largely from data supplied by the institutions themselves in questionnaires sent to all degree-granting regionally accredited colleges and universities and candidates for accreditation in 1996. In addition, information was gleaned from other available sources. The institutions which did not return questionnaires have exhibits prepared from data provided by the National Center for Education Statistics IPED Integrated Post-Secontary Education Database questionnaires, college catalogs, and other institutional sources.

Unless noted, data are for the 1996-97 academic year. Exceptions are as follows: "degrees conferred," which are for 1995-96, "tuition and fees," 1995-96, "financial aid," 1995-96 and "finances" (fiscal year 1996). Changes in addresses, chief executive officers, and admissions officers up to October 1996 are also reflected in the exhibits.

The material throughout Part III was prepared in as set a format as possible to augment comparison of data not only among exhibits in this edition but also to earlier editions of American Universities and Colleges. However, the variety of higher education in America defies formulas, and the exhibits reflect diversity as well as similarity. Whenever possible, qualifications offered by the institutions appear (for example, estimates are so labeled). For the most part, negative information has been omitted. However, exhibits report if institutions conduct no summer sessions, offer no financial aid, especially for foreign students, have no campus housing, or do not permit cars on campus grounds.

Omission of sections from institutional descriptions may indicate negative information, data withheld, or unavailable or irrelevant material.

Characteristics of Institutions. Institutions were asked to provide summary views - control, enrollment, degrees awarded, general relation to statewide coordinating bodies and governing boards, and membership in consortia oriented toward providing student services.

Accreditation. Regional, specialized, and instiutional accreditation is noted.

History. Institutions were asked to provide brief histories followed, where available, by referrals to the best and most comprehensive institutional history available.

Institutional Structure. Institutions were asked to offer a summary view of their governing structure and composition. They were asked to list the number and type of members of the governing board and the number of administrators and faculty in the institution as well as the title of the academic governance body. Faculty represented by collective bargaining agents were so designated.

Calendar. This section indicates the institution's primary calendar system (semester, quarter, etc.) and whether or not summer session is available. It notes the months freshmen may enter and tells when degrees are offered and when commencement occurs.

Characteristics of Freshmen. Institutions were asked to offer information on the entering class (usually freshmen, but sometimes students at other levels in, for example, professional or upper-division-only schools). Institutions were further asked to specify average secondary school rank, SAT or ACT scores if appropriate, and to note number of Merit Scholars attending, number of applicants accepted, number of accepted applicants enrolling, number of freshmen graduating within five years, as well as place of origin of freshmen.

Admission Requirements. Institutions were asked to describe both admission procedures and requirements. Procedures include the type of admission plan (rolling or standard) and the earliest and latest possible application dates, as well as information about the existence of early decision and early acceptance policies. Under the rolling admissions plan, applications are processed as received and the applicants notified when the processing is completed. Early decisions belong to the more traditional admissions plan and provide for a notification of acceptance for highly qualified students in advance of usual admissions notification date. Early acceptance pertains to a policy whereby such students may be admitted at the end of their junior year in high school. Institutions were asked to provide requirements common to their entering class (usually freshmen) as a whole. Requirements are distinguished from recommendations in information on number and distribution of secondary school units, secondary school class standing, GPA, and entrance examinations. Transfer student admission requirements could also be mentioned in this category.

Degree Requirements. Institutions were asked to indicate the levels of degrees for which they were reporting requirements and to list only common requirements. Special requirements often appear in the supplemental exhibits for complex institutions with separate units. Often credit, GPA, and residence requirements are reported as ranges rather than single figures. Institutions were asked to indicate whether students could fulfill requirements through achievement tests, and whether exit examinations, chapel attendance, physical education, or ROTC were required. Finally, institutions were asked to describe their grading systems. In the case of regionally accredited graduate or professional schools, the degree requirements given, like the admission requirements, were those pertaining to programs entered directly following the baccalaureate.

Distinctive Educational Programs. Institutions were asked to report academic offerings such as work-experience programs, including cooperative education and internships; flexible meeting places and schedules, including off-campus centers, weekend and evening classes; accelerated degree plans; dual and joint degree programs involving two institutions and two degrees; doubledegree programs where one institution awards two degrees; cooperative degree programs where two units or institutions offer one degree; external degree programs and continuing education curricula; special facilities for using telecommunications in the classroom; interdepartmental and interdisciplinary programs; study abroad; and many other programs.

ROTC. Institutions were asked to specify whether ROTC was available, whether it was required, and whether it was offered cooperatively with another institution.

Degrees and Other Formal Awards Conferred. Institutions were asked to report degrees at the baccalaureate, master's, and doctoral degree levels in agriculture and nautral resources, architecture and environmental design, area studies, biological sciences, business and management, communications, computer and information sciences, education, engineering, fine and applied arts, health professions, home economics, law, letters, library science, mathematics, military sciences, physical sciences, psychology, public affairs and services, social science, theology, interdisciplinary studies, and other professions. Institutions listed in addition the number of degrees awarded at the associate level in arts and sciences; in science- or engineering-related organized occupational programs in data-processing, health services and paramedical, mechanical and engineering, and natural science technologies; and in other occupational programs in business and commerce, and public service- 
related technologies. Finally, they were asked to report any intermediate degrees-formal recognitions for programs between master's and doctorates which are in essence the doctoral degree without the dissertation.

Fees and Other Expenses. Institutions were asked to provide tuition figures for 1996-97. They were also asked to provide information on fees and room and board.

Financial Aid. Institutions were asked to give the reasons for awarding their undergraduate scholarships, grants, and loans and their graduate fellowships (excluding first-professional awards). They were also asked to report figures on the number of recipients, the total funds awarded, and the range of awards for their undergraduate scholarships, grants, loans, and college-assigned jobs; and for their graduate fellowships (also excluding first-professional) and grants, teaching and research assistantships, and other collegeassigned jobs. They were requested to provide similar information on federal and state aid received by their students.

Departments and Teaching Staff. Institutions were asked to list by department and rank those members of the teaching and research staff (including those with released time) who were employed on a full-time basis and whose major regular assignment was instruction. They were also asked to list part-time teachers who taught less than full time, however that status was defined by the individual institution. In complex institutions with separately defined units such as divisions, schools, or colleges, total faculty figures appear in the main exhibit, with the departmental breakdown available in the descriptions of the individual unit.

Enrollment. Institutions were asked to report their total student enrollment, divided into full- and part-time students at the undergraduate, first professional, and graduate levels. They were also asked to list unclassified students who take courses for credit but are not degree candidates, and numbers of transfer students. In addition, institutions were asked to provide information on the ethnic and racial nature of the student body as well as the age breakdown.

Foreign Students. In this section, institutions were asked to provide information on nonresident aliens in attendance as well as the number of students from various world areas. They were also requested to indicate the availability and extent of the programs, scholarships, fellowships, and loans especially designated for foreign students.

Student Life. Institutions were asked to indicate the presence and nature (particularly whether the dormitories were single-sex or coed) of institutionally provided housing and to describe the availability of married-student housing. They were asked to specify what kinds of intercollegiate athletics were available for men and women; and what kinds of student publications; radio, and television activities were possible. Institutions were asked whether their campus had special regulations regarding cars or residence halls hours. And they were asked to provide information about their medical services, campus transportation systems, and (if appropriate) learning resources centers. Finally, they were asked to characterize the surrounding community as to population and availability of mass transportation.

Publications. If appropriate, institutions were asked to provide information about their scholarly journals and university presses.

Library Collections. Institutions were asked to provide June 1996 figures on their current collections of volumes, government document collections, microforms, audiovisual materials, and periodical subscriptions. They were also asked to describe their three most important special collections and their total budget for 1996-97.

Finances. The institutions were asked to provide financial figures on their revenues from student tuition and fees, state appropriations, local appropriations, restricted and unrestricted private gifts, grants and contracts, and auxiliary enterprises and expenditures and mandatory transfers for instruction, research academic support for libraries, operation and maintenance of plant, restricted and unrestricted scholarships and fellowships and auxiliary enterprises, which give an overall view of their financial situation. The figures requested do not reflect their total expenditures or revenues and therefore do not usually total.

Buildings and Grounds. Institutions were asked to report their campus area, the book value of their buildings, grounds, and equipment, the buildings completed since 1991, the buildings currently being constructed, and the number of buildings.

Chief Executive Officer. The chief executive and admissions officers are, whenever possible, those who held the position in 1996. 